\title{
ANALISA PENENTUAN OPEN END PADA PELAKSANAAN SQUEEZE CEMENTING DI ZONA POROUS SUMUR A LAPANGAN B
}

\author{
Rexnord Samuel Simanungkalit ${ }^{1, a}$ \\ ${ }^{1} J u r u s a n$ Teknik Perminyakan Fakultas Teknik Kebumian dan Energi, \\ Universitas Trisakti, Indonesia \\ afazriapip@gmail.com
}

\begin{abstract}
Abstrak.
Penyemenan adalah proses pendorongan sejumlah bubur semen (slurry) yang mengalir dari bawah sepatu casing hingga naik ke annulus di antara casing dan formasi. Bubur semen tersebut akan mengeras sehingga mengikat antara casing dengan dinding lubang bor. Menurut tujuannya penyemenan dapat dibagi dua, yaitu Penyemenan Awal (Primary Cementing) dan Penyemenan Kedua atau Penyemenan Perbaikan (Secondary atau Remedial Cementing). Apabila pada Primary Cementing hasil penyemenannya belum sempurna dan mengalami masalah, maka akan dilakukan Secondary atau Remedial Cementing. Secondary atau Remedial Cementing dapat dibagi menjadi tiga bagian, yaitu Squeeze cementing, Re-cementing dan Plug-back cementing. Dalam hal ini, penulis lebih menekankan kepada salah satu dari Secondary atau Remedial Cementing yaitu Squeeze cementing.
\end{abstract}

Kata kunci. Cementing, total loss dan squeeze

\begin{abstract}
.
Cementing is the process of pushing a number of slurry which flows from the bottom of the casing shoes to rise to the annulus between the casing and formation. The cement slurry will harden so that it binds between the casing and the borehole wall. According to the purpose of cementing can be divided into two, namely Initial Cementing (Primary Cementing) and Second Cementing or Cementing Repair (Secondary or Remedial Cementing). If the Primary Cementing results are not perfect and have problems, then Secondary or Remedial Cementing will be done. Secondary or Remedial Cementing can be divided into three parts, namely Squeeze cementing, Re-cementing and Plug-back cementing. In this case, the author emphasizes on one of the Secondary or Remedial Cementing namely Squeeze Cementing.
\end{abstract}

Keywords. Cementing, total loss dan squeeze

\section{PENDAHULUAN}

Keberhasilan suatu operasi pemboran dapat dilihat dari keberhasilan dalam pekerjaan penyemenan. Penyemenan berpengaruh dalam kelanjutan umur suatu sumur produksi, apakah diperbaiki atau di tutup. Maka dari itu, perlu perancangan pekerjaan penyemenan yang baik agar kesuksesan dari penyemenan tercapai. Dari beberapa teknik penyemenan, salah satu teknik penyemenan dengan cara memberikan tekanan pada bubur semen (slurry) yang dikenal dengan squeeze cementing. Secara umum, squeeze cementing ialah bubur semen (slurry) yang diberi tekanan hingga terdorong ke bawah sampai pada titik tertentu di dalam sumur untuk perbaikan sumur tersebut. Problem yang sering dihadapi pada sumur minyak ialah pengisolasian air dibawah lubang sumur. Solusinya dengan mempergunakan bubur semen dan penentuan tekanan squeeze. Namun, pada saat ini squeeze cementing juga dipergunakan dalam memisahkan zone penghasil hidrokarbon dari zone yang menghasilkan fluida lainnya. 


\section{Studi Pustaka}

Perumusan masalah yang ditimbulkan dalam penelitian ini adalah seberapa banyak volume bubur semen yang akan digunakan?, seberapa banyak volume displacement yang akan digunakana?, seberapa jauh kita menentukan posisi dari open end pada proses cementing?

\section{METODOLOGI PENELITIAN}

Apabila pekerjaan penyemenan pertama (Primary Cementing) telah dilakukan, dapat dilakukan pengecekan keberhasilan dengan melakukan running CBL (Cement Bond Logging) dan VDL (Variable Density Logging), sehingga dapat diamati sempurna atau terdapat kerusakan. Jika pada hasil logging tersebut terdapat kerusakan maka dilakukan Secondary Cementing. Selain itu, Secondary Cementing dilakukan apabila proses pemboran gagal mendapatkan minyak dan zona produksi yang diperforasi akan ditutup. Penyemenan yang kurang baik dapat membuat operasi pemboran tidak berjalan lancar, sehingga tingkat kualitas dari penyemenan ialah Secondary Cementing. Secondary cementing dibagi menjadi 3 bagian, yaitu :

Squeeze Cementing

Squeeze Cementing adalah proses bubur semen (slurry) yang diberi tekanan hingga terdorong ke bawah sampai pada titik tertentu di dalam sumur untuk maksud perbaikan ikatan semen pada interfal tertentu. Juga mempunyai tujuan untuk : mengurangi water-oil ratio, water gas ratio atau gas-oil ratio, menutup formasi yang tidak lagi produktif, menutup lubang perforasi, menutup zona lost circulation, memperbaiki kebocoran yang terdapat pada casing, memperbaiki primary cementing yang kurang memuaskan.

Pluck-Back Cementing digunakan untuk : menutup atau meninggalkan sumur (abandonment), melakukan directional drilling sebagai landasan whipstok, yang dikarenakan adanya perbedaan compressive strength antara semen dan formasi maka akan mengakibatkan perubahan arah pada bit, menutup zona air di bawah zona minyak agar water oil ratio berkurang pada open hole completion.

Klasifikasi semen berfungsi sebagai pemilihan jenis semen sesuai dengan kondisi surmur dan perlu adanya standarisasi. Klasifikasi ini menggunakan standarisasi API yang mempunyai 9 kelas semen, tergantung kedalaman dan kondisi sumur : Kelas A : Digunakan untuk penyemenan selubung dari kedalaman 0-1830 meter $(6000 \mathrm{ft})$ dengan temperatur $80 \mathrm{o}$ C. semen ini hanya dalam bentuk ordinary atau dengan kata lain semen biasa yang digunakan hanya untuk kondisi normal saja, Kelas B : Digunakan untuk sumur dari kedalaman 0 - 1830 meter $(6000 \mathrm{ft})$ dengan temperatur $80 \mathrm{o} \mathrm{C}$, apabila kondisi formasi membutuhkan tahan sulfat menengah sampai tahan sulfat tinggi, Kelas C : Digunakan untuk sumur dari kedalaman 0 - 1830 meter (6000 ft) dengan temperatur 80o C, apabila kondisi membutuhkan sifat kekuatan awal tinggi, Kelas D : Digunakan untuk sumur dari kedalaman 1830 meter $(6000 \mathrm{ft})$ sampai 3050 meter $(10.000 \mathrm{ft})$ dengan kondisi suhu dan tekanan sedang, Kelas E : Digunakan untuk sumur dari kedalaman 3050 meter (10.000 ft) sampai kedalaman 4270 meter $(14.000 \mathrm{ft})$ dengan kondisi suhu dan tekanan tinggi, Kelas F : Digunakan untuk sumur dari kedalaman 3050 meter (10.000 ft) sampai kedalaman 4880 meter (16.000 ft) dengan kondisi suhu dan tekanan tinggi, Kelas G : Digunakan sebagai semen pemboran dasar untuk kedalaman 2440 meter (8000 ft), atau dapat digunakan dengan akselerator dan retader untuk memperoleh batas jangkauan kedalaman sumur dan suhu yang lebih luas, Kelas H : Digunakan sebagai semen pemboran dasar untuk kedalaman sampai 2440 meter (8000ft) dan dapat digunakan dengan penambahan akselerator dan retarder untuk memperoleh batas jangkauan suhu dan kedalaman sumur yang lebih luas, Kelas J : Digunakan untuk semen dasar pemboran untuk kedalaman 3660 meter (12.000 ft) sampai kedalaman 4880 meter $(16.000 \mathrm{ft})$ pada kondisi suhu dan tekanan yang amat tinggi atau dapat digunakan dengan penambahan akselerator dan retader untuk memperoleh batas jangkauan sumur dan suhu. 


\section{HASIL, PEMBAHASAN DAN ANALISA}

Perencanaan volume bubur semen untuk squeeze cementing dilakukan untuk mengetahui jumlah sack bubur semen dan volume aditifnya.

\section{Volume Bubur Semen Squeeze}

Berdasarkan perhitungan kapasitas diatas kita dapat menghitung volume bubur semen (slurry) yang akan digunakan dengan perhitungan :

Volume Slurry $=(8520 \mathrm{ft}-8470 \mathrm{ft}) \times 0,0383 \mathrm{bbl} / \mathrm{ft}=1,91299 \mathrm{bbl}$

Volume Squeeze $=8,08701 \mathrm{bbl}$

Total $=10 \mathrm{bbl}=56,14 \mathrm{cuft}$

Dengan perhitungan di atas didapat volume bubur semen yang dibutuhkan. Volume tersebut harus diketahui dalam jumlah sak yang akan digunakan dengan cara :

Jumlah Sak $=\frac{56,14 \text { cuft }}{1,175}=47,7$ sak $=48$ sak

Mixing Water $=48$ sak $\times(5,251 / 42)=6 \mathrm{bbl}$

Excees $10 \%=2 \mathrm{bbl}$

Total $=48 \mathrm{sak}+((6 \mathrm{bbl}+2 \mathrm{bbl}) \times(5,251 / 42))=64 \mathrm{sak}$

Maka dari keseluruhan perhitungan tersebut didapat jumlah sak semen yang dibutuhkan ialah sebanyak 64 sak. Berdasarkan jumlah sak tersebut kita dapat memperhitungkan bahan aditif yang akan ditambahkan kedalam kedalam bubur semen. Untuk memperhitungkan konsentrasi dari aditif tersebut dengan cara : Konsentrasi = (Material S.G/Berat) / 8,878 (\%)

\begin{tabular}{|c|c|c|c|c|c|}
\hline Kode & $\begin{array}{c}\text { Berat } \\
(\mathrm{ppg})\end{array}$ & Material S.G & $\begin{array}{c}\text { Volume } \\
(\mathrm{bbl})\end{array}$ & $\begin{array}{c}\text { Konsentrasi } \\
(\%)\end{array}$ & Nama \\
\hline PC-X61L & 1 & 0,6 & 0,6 & 0,068 & Defoamer \\
\hline PC-G71L & 1,05 & 12 & 11,429 & 1,287 & Fluid Loss \\
\hline PC-GS2L & 1,36 & 5 & 3,676 & 0,414 & Anti-gas Migration \\
\hline PC-F41L & 1,17 & 0,3 & 0,256 & 0,029 & Dispersant \\
\hline PC-H31L & 1,06 & 0,4 & 0,377 & 0,043 & Retarder \\
\hline
\end{tabular}


Berikut perhitungannya :

$\begin{array}{cll}\text { Additif }=64 \times 0,0680 \% & =4,3252 \mathrm{gal} & \text { (Defoamer) } \\ 64 \times 1,287 \% & =82,38 \mathrm{gal} & \text { (Fluid Loss) } \\ 64 \times 0,414 \% & =36,5 \mathrm{gal} & (\text { Anti Gas Migration) } \\ 64 \times 0,029 \% & =1,848 \mathrm{gal} & \text { (Dispersant) } \\ 64 \times 0,043 \% & =2,72 \mathrm{gal} & \text { (Retarder) }\end{array}$

Selain memperhitungkan volume bubur semen (slurry) dalam jumlah sak, maka harus diperhitungkan juga displacement dari sumur tersebut. Pengertian displacement ialah panjang pendesakan bubur semen hingga sampai target. Perhitungan tersebut dilakukan dengan cara :

Top of Cement String In $\quad: 8520 \mathrm{ft}-(10 /(0,0087+0,0264))=8234,652 \mathrm{ft}$

Top of Cement String Out $\quad: 8520 \mathrm{ft}-(10 / 0,0383)=8258,6284 \mathrm{ft}$

Water Ahead $\quad$ : 10 bbl @7911,6 ft MD

Water Behind $\quad$ : $(10 / 0,0613) \times 0,0087=1,41 \mathrm{bbl} @ 7911,6 \mathrm{ft} \mathrm{MD}$

Displacement

- Inside 3-1/2 DP : $(8520 \mathrm{ft}-(15 \times 60)) \times 0,0074=56,388 \mathrm{bbl}$

- Inside 3-1/2 Tubing : $(8234 \mathrm{ft}-(8520 \mathrm{ft}-(15 \times 60))) \times 0,0058=3,5 \mathrm{bbl}$

- Underdisplace : $2 \mathrm{bbl}$

Total Displacement $\quad:(56,388 \mathrm{bbl}+3,5 \mathrm{bbl})-2 \mathrm{bbl}=57,953 \mathrm{bbl}=58 \mathrm{bbl}$

\section{Posisi Open End}

Perencanaan penentuan open end dilakukan untuk mengetahui posisi dari open end agar pada saat semen yang akan dipompakan tidak habis tertelan oleh zona yang poros melainkan semen itu akan settling sesuai dengan thickening time semen tersebut Jika

Tcc $=$ Cement Consuming Time (waktu yang dibutuhkan semua formasi untuk semen tertelan formasi

Tcs = Cement Setting Time (waktu yang dibutuhkan untuk semen mongering)

Tcs dapat diperoleh dari cementing engineer berdasarkan laboratorium test Tcc diestimasi oleh cementing engineer berdasarkan injectivity

Dari pemahaman tersebut maka terdapat dua kesimpulan agar semen saat kering belum tertelan semua kedalam formasi, yaitu: memperbesar Cement Consuming Time (Tcc), memperkecil Cement Setting Time (Tcs)

Kedua hal tersebut dapat diwujudkan dengan berbagai cara, yang akan dijelaskan satu persatu Analogy Injectivity Berdasarkan Productivity Idex (PI)

Anggap bahwa: friksi akibat arsitektur porosity dapat diabaikan, volume injeksi < volume fluida di reservoir maka compresi akibat injeksi dapat diabaikan

Maka injectivity adalah sama dengan PI hanya berbeda arah saja. 
Dengan konsep ini maka kita dapat memprediksi loss rate pada $\mathrm{P}$ tertentu yang kita ciptakan.

Loss rate $=$ Injectivity $\times \Delta \mathrm{p}=\mathrm{PI} \times \Delta \mathrm{P}$

Jika $\Delta \mathrm{p}=50 \mathrm{psia}$ dan $\mathrm{PI}=50 \mathrm{bbl} /$ day $/$ psia

Maka Loss rate $=50 \times 50=2500 \mathrm{bbl} /$ day pada $\Delta \mathrm{p}$ tersebut

Tujuan dari pemikiran ini adalah menentukan dimana semen harus di drop sehingga pada saat tekanan hidrostatik sumur sama tekanan statik formasi , top semen masih ada didalam sumur.

Alur Perhitungan

- Top perforation

$$
\begin{aligned}
& =8470 \mathrm{ft} \mathrm{MD} \\
& =7788,89 \mathrm{ft} \text { TVD } \\
& =100 \mathrm{ft} \text { height }
\end{aligned}
$$

- Hc (expected cement coloum height when setting)

- Expected top of cement after setting

(Pada kondisi tekanan statik formas $=$ tekanan hidrotatik sumur) $=7688,89 \mathrm{ft}$ TVD

- $\quad \rho$ cement (cement density)

$$
=8355.96 \mathrm{ft} \mathrm{MD}
$$

- Hp cement (cement hydrostatic pressure) $(0,052 \times \rho \mathrm{c} \times \mathrm{hc})$

$$
0,052 \times 10 \times 100=82,16 \mathrm{psia}
$$

- Volume lubang dari permukaan sampai top cement

- Estimated volume fill up selama cementing

$=8492,09$ cuft

- Vd (displacement volume)

$=10 \mathrm{bbl}$

$=58 \mathrm{bbl}$

- Volume lubang dari surface sampai top dispalcement

Volume lubang dari surface sampai top displacement$(5,6 \times(V d+$ Volume fill up $)$

$$
=8111,29 \text { cuft }
$$

- Depth of top displacement

$$
\begin{aligned}
& =6746,09 \mathrm{ft} \mathrm{MD} \\
& =6249,28 \mathrm{ft} \text { TVD }
\end{aligned}
$$

- $\quad$ dv (displacement volume density)

$$
=12 \mathrm{ppg}
$$

- Hpdv (displacement volume hydrostatic pressure)

$0,052 \times \rho d v \times$ (Expected top of cement after setting -

Depth of top displacement TVD)

- Static formation pressure

$=898,32$ psia

$=2561$ psia

- $\Delta p=\operatorname{Pr}-(\mathrm{Hpdv}+\mathrm{Hpc})$

- $\quad$ ocf (completion fluid density)

Selisih ketinggian kolom di dalam open end string dengan Annulus $=220 \mathrm{ft}$ height

ID open end string $\quad=2,988$ inch

OD open end string $=3,5$ inch

ID surface casing $\quad=8,535$ inch

- Kenaikan level di annulus akibat U-Tube effect

((ID Open end string $\left.{ }^{2}\right) \times$ Selisih ketinggian kolom di dalam open end string dengan Annulus $) /\left(\left(I D\right.\right.$ open end string $\left.{ }^{2}\right)+\left(I D\right.$ surface casing $\left.{ }^{2}\right)-\left(O D\right.$ open end string $\left.{ }^{2}\right)=38,75 \mathrm{ft}$ height 
Estimasi kenaikan tekanan annulus selama menunggu semen kering $(\mathrm{WOC})=100$ psia (kenaikan tekanan di annulus akan mendorong level cairan didalam sumur turun menjadi lebih dalam, sehingga ini penting untuk dipertimbangkan untuk memastikan top cement masih berada di dalam sumur)

Depth of cement drop point from top coloum di sumur

$(\Delta \mathrm{p} /(0,052 \times \rho \mathrm{cf}))$ - Kenaikan level di annulus akibat $U$-Tube effect $-(\mathrm{WOC} /(0,052 \times \rho \mathrm{cf}))=3272 \mathrm{ft}$ TVD

\section{KESIMPULAN}

Pelaksanaan squeeze cementing membutuhkan volume bubur sebanyak $10 \mathrm{bbl}$ dengan total 64 sack dan posisi dari open end pada pelaksanaan squeeze cementing ialah $3272 \mathrm{ft}$ TVD.

\section{DAFTAR PUSTAKA}

[Gatrin, Carl. 1960 “ Petroleum Engineering Drilling And Well Completion”. New Jersy: Pretentice Hall, Inc.

Hodges, J. W. 1989. "Squeeze Cementing Methods and Materials,". Lubbock: SPE Squeeze Symposium.

Howard, G. C., Fast, C. R. 1980. “Squeeze Cementing Operations,” Trans., AIME 189, 53-64.

http://en.wikipedia.org/wiki/Squeeze_job

http://exel.com.pl/exel/index.php?page=float-shoe-collars

http://summitcasing.com/products/

http://www.bridge7.com/grand/log/gen/casedhole/cbl.htm

http://www.jereh-oilfield.com/english/products/Casing-Guide-Shoes.\%20shtm

http://www.msi-sa.biz/engineered-products.php

http://www.niobrarareport.com/wp-content/uploads/

http://www.revataengineering.com/top-bottom-cementing-plugs.htm

http://www.thrutubingsystems.com/intervention-products-and-services.php?product=/sand-controlsystems/

http://www.halliburton.com/en-US/ps/cementing/land-equipment/pumping-mixing-equipment/

http://en.wikipedia.org/wiki/Cementing_equipment

http://abdulrohim-betawi.blogspot.com/2011/04/cementing.html

Maps of JOB Pertamina-Petrochina East Java 